\title{
PELATIHAN PENATALAKSANAAN PREHOSPITAL HENTI JANTING DAN ANAK DEMAM DENGAN KONSEP SAFE COMMUNITY DI KOTA LUBUKLINGGAU
}

\author{
DOI: https://doi.org/10.33024/jkpm.v4i5.4248 \\ Sapondra Wijaya ${ }^{1}$, Bambang Soewito ${ }^{2}$ \\ ${ }^{1,2}$ Dosen Prodi Keperawatan Lubuklinggau Poltekkes Kemenkes Palembang \\ Disubmit: 20 April 2021 Diterima: 03 Mei 2021 Diterbitkan: 01 Oktober 2021 \\ Email: ondra@poltekkespalembang.ac.id
}

\begin{abstract}
ABSTRAK
Kasus kegawatan medis dapat terjadi dimana dan kapan saja, salah satunya adalah henti jantung dan demam anak. Akan sangat berbahaya kejadian yang terjadi di lingkungan masyarakat yang tidak ada orang yang mampu memberikan pertolongan pertama, ataupun tidak tahu kemana akan mencari pertolongan. Kesalahan memberikan pertolongan bisa membuat pasien menjadi lebih menderita dan meninggalkan kecacatan. Keadaan diatas memerlukan pertolongan yang baik dan segera sebelum pasien dibawa ke rumah sakit untuk perawatan definitif. Permasalahan muncul karena tidak banyak orang awam di yang bisa memberikan pertolongan pertama pada kejadian tersebut dan ketidaktahuan akan sistem pengaduan kasus tersebut. Kegiatan ini dilaksanakan dengan metode demonstrasi dan praktik agar partisipan memiliki pengetahuan dan keterampilan pertolongan pada henti jantung dan demam pada anak. Selain itu butuh pembuatan sebuah sistem sederhana berbasis komunitas sebagai alur awal pertolongan pasien, dengan sistem ini masyarakat mengetahui kemana mereka harus melapor. Semua rangkaian kegiatan tersebut dengan tujuan membentuk sebuah komunitas yang aman yang disebut "Safe Community". Dari pelaksanaan kedua pelatihan tersebut di atas, terdapat peningkatan pengetahuan dan keterampilan masyarakat dalam memberikan pertolongan henti jantung dan demam anak yaitu sebesar rata-rata 23 poin dalam skala 100.
\end{abstract}

Kata Kunci: Henti Jantung, Kejang Demam, Safe Community

\begin{abstract}
Medical emergency cases can occur anywhere and anytime, one of which is cardiac arrest and childhood fever. It would be very dangerous to happen in a community where no one is able to provide first aid, or does not know where to go for help. Mistakes in providing help can make patients suffer more and leave disabilities. The above conditions require good and immediate assistance before the patient is admitted to the hospital for definitive treatment. The problem arose because there were not many ordinary people who could provide first aid to the incident and they were ignorant of the complaint system for the case. This activity is carried out with demonstration and practical methods so that participants have the knowledge and skills to help with cardiac arrest and fever in children. In addition, it is necessary to create a simple community-based
\end{abstract}


system as the initial flow of patient assistance, with this system the community knows where they have to report. All of these series of activities are aimed at forming a safe community called "Safe Community". From the implementation of the two trainings above, there is an increase in the knowledge and skills of the community in providing assistance for cardiac arrest and child fever, which is an average of 23 points on a scale of 100.

Keywords: Cardiac Arrest, Febrile Convulsion, Safe Community

\section{PENDAHULUAN}

Kasus kegawatan medis dapat terjadi dimana dan kapan saja. Akan sangat berbahaya kejadian yang terjadi di lingkungan masyarakat yang tidak ada orang yang mampu memberikan pertolongan pertama, ataupun tidak tahu kemana akan mencari pertolongan. Kegawatan yang paling sering terjadi di area komunitas adalah kecelakaan yang diakibatkan oleh trauma, kegawatan pada kasus anak, dan henti jantung. Ketiga keadaan diatas memerlukan pertolongan yang baik dan segera sebelum pasien dibawa ke rumah sakit untuk perawatan definitif. Kesalahan memberikan pertolongan bisa membuat pasien menjadi lebih menderita dan meninggalkan kecacatan demi drajat kesehatan masyarakat yang meningkat.

Untuk meningkatkan kesehatan masyarakat dibutuhkan sudut pandang baru, yaitu menggeser perawatan kesehatan dari rumah sakit pada tingkat pelayanan kesehatan primer, keluarga dan masyarakat (Underwood et al., 2009). Butuh pembuatan sebuah sistem sederhana berbasis komunitas sebagai alur awal pertolongan pasien, dengan sistem ini masyarakat mengetahui kemana mereka harus melapor. Semua rangkaian kegiatan tersebut dengan tujuan membentuk sebuah komunitas yang aman yang disebut "Safe Community".

Safe community adalah kondisi aman dan sehat dalam seluruh siklus kehidupan manusia sejak dalam kandungan sampai usia lanjut (Direktorat Bina kesehatan Komunitas). Safe community merupakan suatu gerakan: dari masyarakat, oleh masyarakat dan untuk masyarakat. Wacana safe community ini berkembang sesuai dengan tuntutan atas peningkatan kualitas pelayanan, khususnya pelayanan kedaruratan medis. Safe community secara sistem di mulai tingkat desa, Pustu, puskesmas sampai pelayanan kedaruratan di Rumah sakit (Departemen kesehatan RI 2006). Istilah Safe Community menyiratkan bahwa komunitas menginginkan keselamatan dalam pendekatan terstruktur untuk keselamatan mereka sendiri (Price, 2010).

Tujuan terbentuknya model safe community berbasis masyarakat agar tercapai kondisi masyarakat aman dan sehat dalam seluruh siklus kehidupan manusia pada keadaan gawat darurat sehari-hari maupun bencana (Pratiwi et al, 2011). Pelatihan pertolongan pertama henti jantung dan diare pada anak fase pre hospital bagi masyarakat Perumahan Grand Mulya II yang berisiko untuk menyiapkan Safe Community.

Pada penyiapan Safe Community banyak hal yang harus dipelajari masyarakat agar mereka bisa berdaya guna untuk mereka sendiri, dari mulai penanganan trauma, kardiovaskular, sampai kegawatan-kegawatan yang biasa terjadi di rumah tangga. Pada kesempatan ini kami akan melakukan pemberian informasi sekaligus melatih masyarakat Perumahan Grand Mulya II dalam penanganan kejang demam dan kejadian henti jantung yang terjadi di luar rumah sakit. 


\section{MASALAH}

Perumahan Grand Mulya II Kota Lubuklinggau adalah perumahan subsidi dengan jumlah 80 rumah. Dari keseluruhan masyarakat perumahan, $90 \%$ adalah keluarga dengan anak balita dan sekolah dasar.

Hasil studi pendahuluan Dari studi awal yang langsung dilaksanakan ke beberapa warga, didapati bahwa mereka belum mengetahui bagaimana cara menangani pasien di fase pre hospital, terutama keluarga mereka sendiri. Penanganan pre hospital yang dimaksud disini adalah bagaimana cara menolong pertama pada kecelakaan dan kegawatan, kegawatan pada anak, dan pelaksanaan bantuan hidup dasar. Menurut warga terdapat beberapa kejadian yang mereka tidak mengetahui penanganannya sehingga menimbulkan korban, seperti anak meninggal karena kejang demam, bagaimana menanganai luka bakar dengan baik agar lukanya bagus, dan lain sebagainya

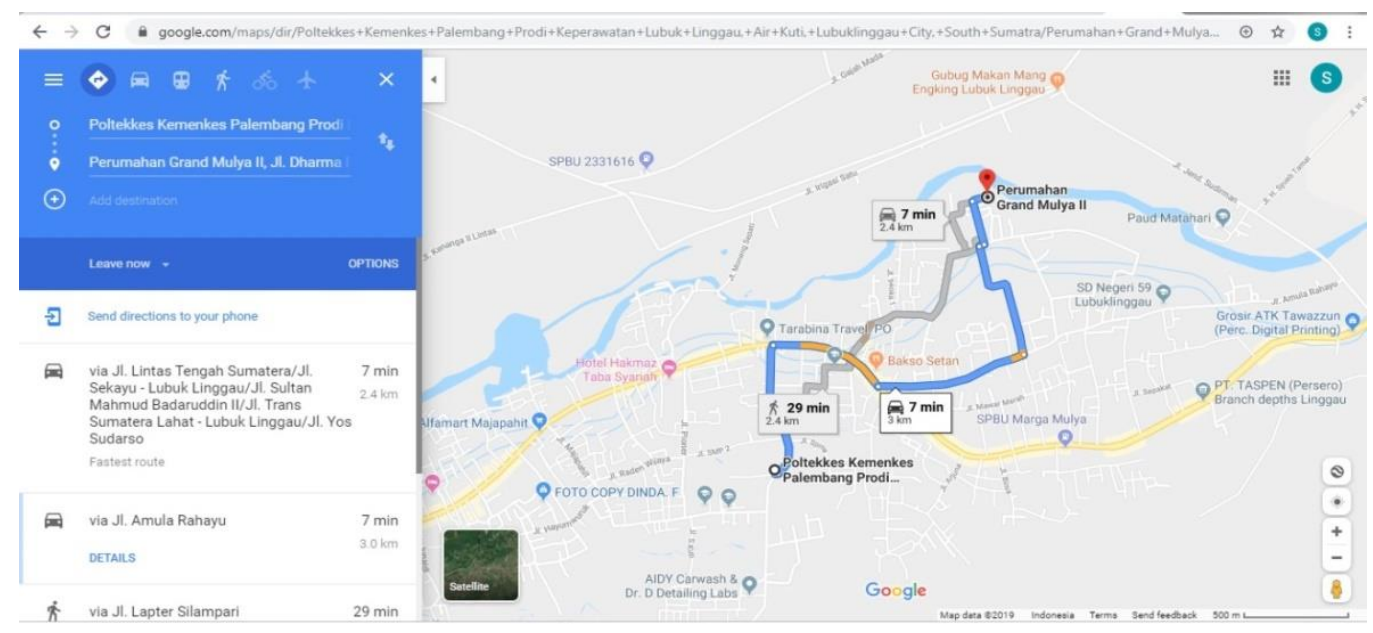

Gambar 2.1. Peta Lokasi Perumahan GM II Kota Lubuklinggau

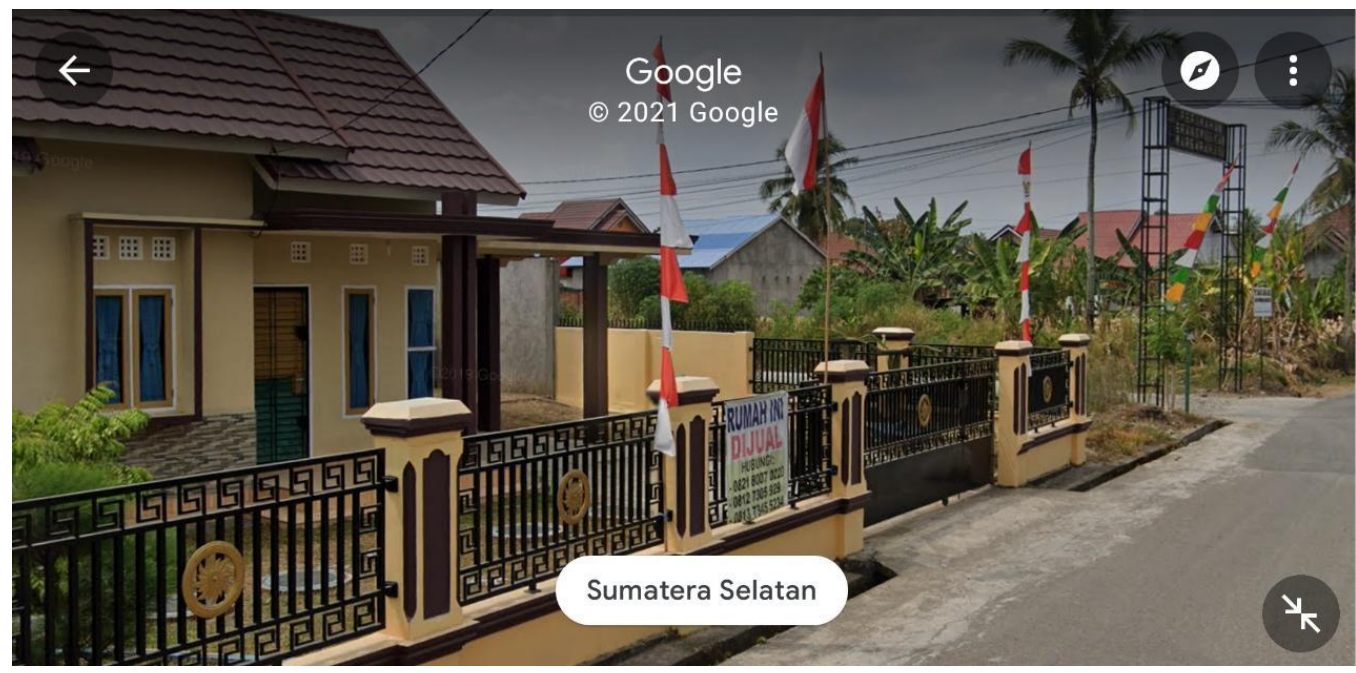

Gambar 2.2. Gambar Gerbang Masuk Perumahan GM II Kota Lubuklinggau 


\section{METODE}

a. Tahapan Persiapan

Persiapan dalam pengabdian masyarakat ini adalah mencari jadwal yang pas untuk kegiatan Pelaksanaan kegiatan ini yang dilaksanakan dalam 2 (Dua) Tahap, yaitu pada tanggal 09 Oktober 2020 berjudul diklat tentang penanganan anak demam dan kejang demam di rumah dengan peserta ibu-ibu, dan tanggal 23 Oktober 2020 berjudul penanganan henti jantung pre hospital dengan peserta bapak-bapak. Total jumlah peserta adalah 80 orang dengan masing-masing kegiatan 40 orang.

Setelah menentukan jadwal, tim pelaksana menyiapkan materi berupa leaflet kejang demam, video Hands Only CPR dan Manekin CPR untuk kegiatan pengabdian masyarakat

b. Tahapan Pelaksanaan

1) Tahap 1 (Diklat tentang penanganan kejang demam di rumah)

Peserta hadir sesuai kesepakatan di rumah salah satu kader, kemudian diawali dengan pre test, dilanjutkan diklat penatalaksanaan kejang demam, kemudian diakhiri dengan post test untuk mengukur kemajuan yang didapatkan.

2) Tahap 2 (Penanganan henti jantung pre hospital)

Peserta hadir sesuai kesepakatan di rumah salah satu kader, kemudian diawali dengan pre test, dilanjutkan diklat penatalaksanaan henti jantung, selanjutnya tim pelaksana melakukan demonstrasi dan redemontrasi ke peserta pelatihan. Kegiatan diakhiri dengan post test untuk mengukur kemajuan yang didapatkan.

\section{HASIL DAN PEMBAHASAN}

a. Hasil

1) Pendidikan dan Pelatihan Penatalaksanaan Demam anak Prehospital

a) Analisa Deskripsi Responden

Tujuan analisis deskriptif digunakan untuk mengetahui gambaran umum responden. Hasil analisis deskriptif responden tersaji pada Tabel 4.1 merupakan ringkasan karakteristik responden berdasarkan Usia, Jenis Kelamin dan Pendidikan responden.

Tabel 4.1. Hasil Analisis Deskriptif Responden

\begin{tabular}{|c|c|c|c|}
\hline \multirow{2}{*}{\multicolumn{2}{|c|}{ Karakteristik Responden }} & \multicolumn{2}{|c|}{ Kelingi } \\
\hline & & \multirow{2}{*}{$\begin{array}{c}\text { Freq } \\
8\end{array}$} & \multirow{2}{*}{$\begin{array}{c}\% \\
27 \%\end{array}$} \\
\hline Umur & 21-30 tahun & & \\
\hline & 31-40 tahun & 19 & $63 \%$ \\
\hline & 41-50 tahun & 3 & $10 \%$ \\
\hline \multirow[t]{4}{*}{ Pendidikan } & SMP & 3 & $10 \%$ \\
\hline & SMA & 12 & $40 \%$ \\
\hline & D3 & 7 & $23 \%$ \\
\hline & S1 & 8 & $27 \%$ \\
\hline
\end{tabular}


b) Perbandingan Nilai Rata-Rata Pengetahuan

Tabel 4.2. Perbandingan Rata-Rata Nilai Pengetahuan

\begin{tabular}{|r|l|c|}
\hline \multicolumn{1}{|c|}{ No } & \multicolumn{1}{|c|}{ Perlakuan } & $\begin{array}{c}\text { Rata-Rata } \\
\text { Nilai }\end{array}$ \\
\hline 1. & Sebelum melakukan pelatihan dan penyuluhan & 58.27 \\
\hline 2. & Sesudah melakukan pelatihan dan penyuluhan & 74.00 \\
\hline
\end{tabular}

Tabel 4.1 dan 4.2 menunjukkan bahwa mayoritas subjek (63\%) berusia 31 40 tahun dan pendidikan subjek mayoritas SMA (40\%). Table diatas juga menunjukkan bahwa rata-rata nilai pengetahuan masyarakat sebelum dan sesudah diberi pelatihan. Sebelum diberi penyuluhan dan pelatihan rata-rata nilai pengetahuan dari 30 orang adalah 58.27, sementara setelah diberi penyuluhan dan pelatihan rata-rata nilai pengetahuan adalah sebesar 74.00. Hal ini mengindikasikan bahwa terdapat peningkatan pengetahuan masyarakat terhadap masalah Demam yang dialami anak di rumah, dimulai dari tanda gejala penanganan awal serta tindakan yang harus dilakukan berdasarkan kondisi anak.

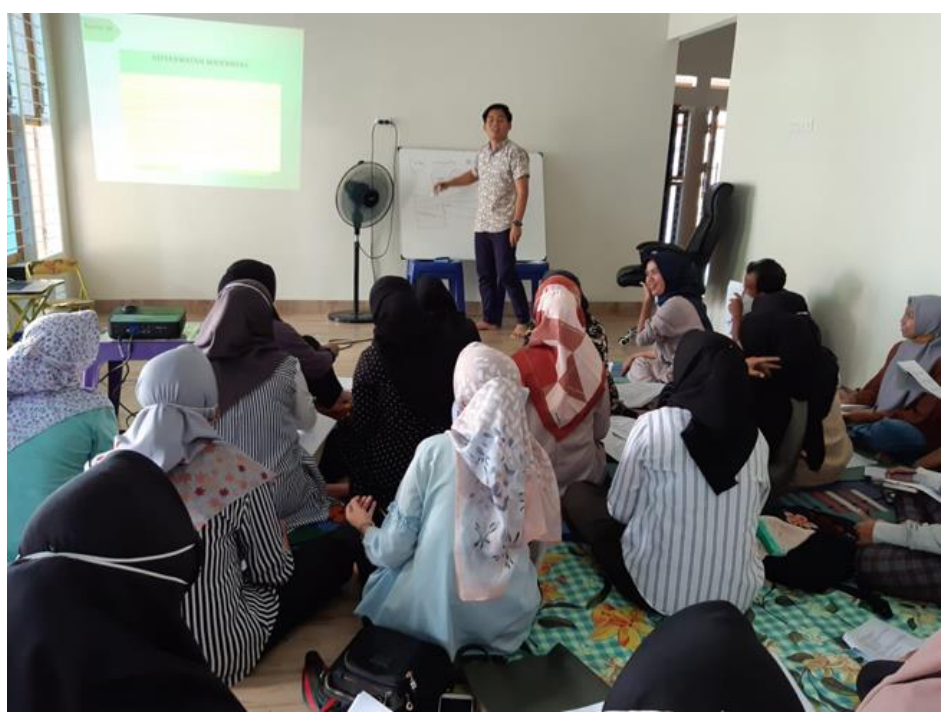

2) Pendidikan dan Pelatihan Hands Only CPR

a) Analisa Deskripsi Responden

Tujuan analisis deskriptif digunakan untuk mengetahui gambaran umum responden. Hasil analisis deskriptif responden tersaji pada Tabel 4.1 merupakan ringkasan karakteristik responden berdasarkan Usia, Jenis Kelamin dan Pendidikan responden.

Tabel 4.3. Hasil Analisis Deskriptif Responden

\begin{tabular}{|l|l|c|c|}
\hline \multirow{2}{*}{ Karakteristik Responden } & \multicolumn{2}{c|}{ Kelingi } \\
\cline { 3 - 4 } \multicolumn{2}{|c|}{ Umur } & Freq & $\%$ \\
\cline { 2 - 4 } & $21-30$ tahun & 8 & $27 \%$ \\
\cline { 2 - 4 } & $31-40$ tahun & 16 & $53 \%$ \\
\cline { 2 - 4 } & $41-50$ tahun & 6 & $20 \%$ \\
\hline Pendidikan & SMP & 1 & $10 \%$ \\
\cline { 2 - 4 } & SMA & 12 & $40 \%$ \\
\cline { 2 - 4 } & D3 & 16 & $53 \%$ \\
\cline { 2 - 4 } & S1 & 2 & $7 \%$ \\
\hline
\end{tabular}


b) Perbandingan Nilai Rata-Rata Pengetahuan

Tabel 4.4. Perbandingan Rata-Rata Nilai Pengetahuan

\begin{tabular}{|r|l|c|}
\hline No & \multicolumn{1}{|c|}{ Perlakuan } & $\begin{array}{l}\text { Rata-Rata } \\
\text { Nilai }\end{array}$ \\
\hline 3. & $\begin{array}{l}\text { Sebelum melakukan pelatihan dan } \\
\text { penyuluhan }\end{array}$ & 45.27 \\
\hline 4. & $\begin{array}{l}\text { Sesudah melakukan pelatihan dan } \\
\text { penyuluhan }\end{array}$ & 76.00 \\
\hline
\end{tabular}

Tabel 4.3 dan 4.4 menunjukkan bahwa mayoritas subjek (53\%) berusia 31-40 tahun dan pendidikan subjek mayoritas D3 (53\%). Tabel di atas juga menunjukkan bahwa rata-rata nilai pengetahuan masyarakat sebelum dan sesudah diberi pelatihan. Sebelum diberi penyuluhan dan pelatihan rata-rata nilai pengetahuan dari 30 orang adalah 45.27, sementara setelah diberi penyuluhan dan pelatihan rata-rata nilai pengetahuan adalah sebesar 76.00. Hal ini mengindikasikan bahwa terdapat peningkatan pengetahuan masyarakat terhadap masalah Henti Jnautng, dimulai dari tanda gejala penanganan awal serta tindakan yang harus dilakukan.

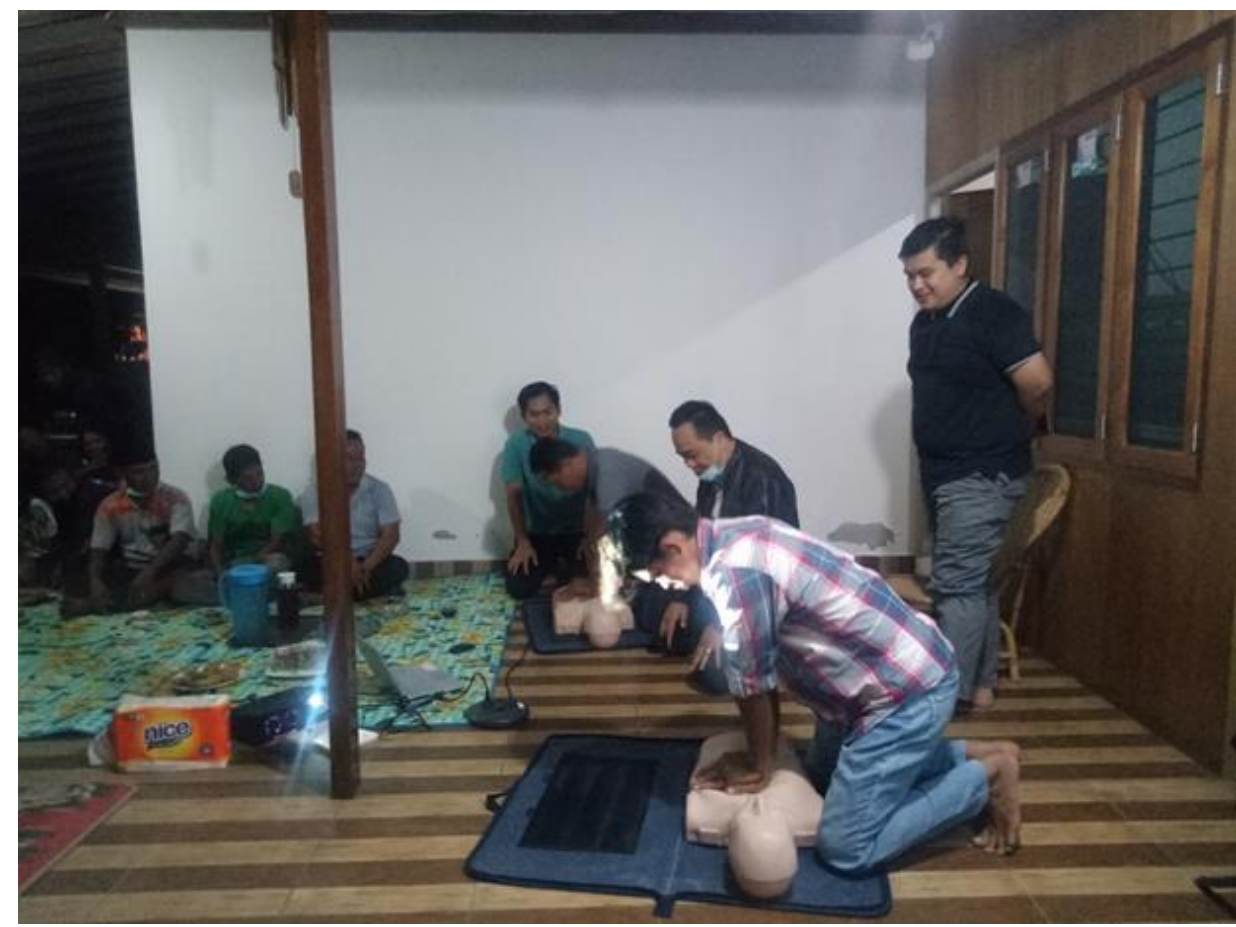

\section{b. Pembahasan}

Tujuan dari pendidikan kesehatan adalah terjadinya perubahan pengetahuan, sikap dan tingkah laku individu, keluarga, kelompok khusus, dan masyarakat (Nursalam \& Efendi, 2008), artinya teori ini sesuai dengan hasil analisa pengetahuan pre dan post tes yang terdapat peningkatan. Peningkatan pengetahuan yang dibahas disini adalah pengetahuan tentang penatalaksanaan kejang demam dan penatalaksanaan henti jantung.

Dalam masyarakat pendidikan dan pelatihan tidak serta merta bisa terlaksana dalam jangka panjang, dikarenakan keterbatasan sumber daya. Penyuluhan dan workshop singkat merupakan salah satu solusi paling efektif. 
Penyuluhan kepada masyarakat bisa meningkatkan pengetahuan masyarakat tentang informasi kesehatan (Juniarti, et al. 2017).

Meningkatnya pengetahuan diharapkan akan menjadi dasar terbentuknya Safe Community. Salah satu dasar dari safe community adalah pengetahuan, keterampilan, sikap dan kebiasaan masyarakatnya (Hanson, et al, 2015). Diharapkan dengan meningkatnya pengetahuan dan keterampilan kesehatan akan mengubah sikap dan kebiasaan masyarakat jika seseorang dalam lingkungannya mengalami masalah kesehatan. Sebuah penelitian menyebutkan ada penurunan cidera pada anak setelah dijalankan program safe community (Lindkvist \& Dalal, 2012)

Kegiatan pengabdian masyarakat ini juga merupakan sebuah upaya untuk pemberdayaan masyarakat dalam menyebarkan informasi kesehatan yang biasa disebut kader. Strategi promosi kesehatan untuk mengatasi persoalan yang terkait dengan kesehatan yaitu pemberdayaan atau empowerment, dengan masyarakat sebagai sasaran utama kegiatan promosi kesehatan (Rodiah, et al. 2016).

\section{KESIMPULAN}

Kegiatan pengabdian masyarakat ini merupakan langkah dalam pembentukan safe community. Pelaksanaan kegiatan pengabmas ini berhasil meningkatkan pengetahuan dan keterampilan masyarakat Perumahan Grand Mulya II dalam penatalaksaan kejang demam dan henti jantung di fase pre hospital.

Kegiatan ini diharapkan akan menjadi dasar dari perubahan prilaku dan kebiasaan dalam menolong sesame dengan tujuan safe community. Kita perlu menciptakan lingkungan yang bertanggung jawab atas keadaan mereka sendiri, yang merasa jika mereka berkumpul bersama dan terlibat, mereka dapat membentuk dunia di sekitar mereka (Price, 2010).

\section{DAFTAR PUSTAKA}

Departemen Kesehatan RI. (2006). Pedoman Desa Siaga, Pusat Promosi Kesehatan-Dep.Kes RI.

Direktorat Bina kesehatan Komunitas: Kebijakan safe community (Awam), Dinas Kesehatan Provinsi Dinas Kesehatan Provinsi Jatim.

Hanson, D., Gunning, C., Rose, J., McFarlane, K., dan Franklin, R, C. (2015). Working From the Inside Out: A Case Study of Mackay Safe Community. Health Education \& Behavior 2015, Vol. 42(1S) 35S-45S https://journals.sagepub.com/doi/abs/10.1177/1090198114568305

Juniarti, N., Haroen, H., dan Yani, D, I. (2016). Upaya Penguatan Pelayanan Kesehatan Primer Pada Anak Sekolah Di Pangandaran. Jurnal Pengabdian Kepada Masyarakat Vol. 1, No. 4, Agustus 2017: 232 - 235 http: / / jurnal.unpad.ac.id/pkm/article/view/16402

Lindqvist, K., \& Koustuv Dalal, K. (2012). The impact of child safety promotion on different social strata in a WHO Safe Community. J Inj Violence Res. 2012 Jan; 4(1): 20-25. doi: 10.5249/jivr.v4i1.83 https: //www.ncbi.nlm.nih.gov/pmc/articles/PMC3291282/

Nursalam \& Efendi, F. (2008). Pendidikan Dalam Keperawatan. Jakarta : Salemba Medika.

Pratiwi, N. L., Rahanto, S., Pranata, S., Pramono, S., Wulansari, S., Purbaningrum, V., Fauziah, Y., dan Lestari, W. (2011). Pengembangan 
Model Safe Community Berbasis Masyarakat. Buletin Penelitian Sistem Kesehatan - Vol. 14 No. 1 Januari 2011: 75-83 https: / /www.neliti.com/publications/21258/pengembangan-model-safecommunity-berbasis-masyarakat

Price, Averile. (2010). Chelmsford Borough Council: A designated International Safe Community. Commonwealth Journal of Local Governance. Issue 7: November 2010 http://epress.lib.uts.edu.au/ojs/index.php/cjlg

Rodiah S., Lusiana E. dan Agustine M. (2016). Pemberdayaan Kader Pkk Dalam Usaha Penyebarluasan Informasi Kesehatan Jatinangor. Dharmakarya: Jurnal Aplikasi Ipteks untuk Masyarakat Vol. 5, No. 1, Mei 2016: 5 - 8 http://journal.unpad.ac.id/dharmakarya/article/view/9923

Underwood, J. M., Mowat, D. L., Meagher-Stewart, D. M., Deber, R. B., Baumann, A. O., MacDonald, M. B., Munroe, V. J. (2009). Building community and public health nursing capacity: A synthesis report of the national community health nursing study. Canadian Journal of Public Health, 100(5), I-1(24). https: //pubmed.ncbi.nlm.nih.gov/19994738/ 